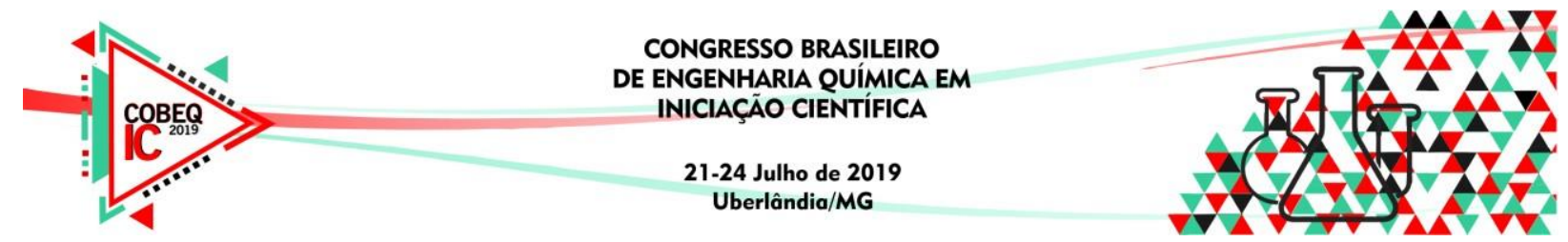

\title{
REVESTIMENTO COM FILMES COMESTÍVEIS À BASE DE QUITOSANA E GLICEROL PARA EXTENSÃO DA VIDA DE PRATELEIRA DE MORANGOS
}

\author{
A. V. A. MATTOS ${ }^{1}$, A. PAVINATTO ${ }^{2}$, A. C. G. MALPASS ${ }^{1}$, M. H. OKURA ${ }^{1}$ e R. C. \\ SANFELICE ${ }^{1}$ \\ ${ }^{1}$ Universidade Federal do Triângulo Mineiro, Departamento de Engenharia Química \\ ${ }^{2}$ Universidade Brasil, Instituto Científico e Tecnológico da Universidade Brasil \\ E-mail para contato: aleexiaa-mattos@hotmail.com
}

\begin{abstract}
RESUMO - O presente trabalho consiste no desenvolvimento de filmes à base de quitosana para aplicação como camada protetora de alimentos e produtos naturais, como frutas e vegetais. A quitosana é um biopolímero particularmente conhecido por suas propriedades antibacterianas e antifúngicas que, quando combinadas com sua biocompatibilidade e biodegradabilidade, podem ser amplamente aplicada em áreas como cosmética, farmacêutica e alimentícia. A formação de filmes nanoestruturados finos e ultrafinos traz vantagens para a manipulação e uso de polímeros. Neste trabalho, filmes finos à base de quitosana foram obtidos pelo método de drop-casting utilizando glicerol como plastificante. Diferentemente dos filmes de quitosana pura, os filmes contendo glicerol apresentaram maior elasticidade e caráter hidrofóbico. Tais propriedades são desejáveis para formar uma camada protetora que não seja totalmente solúvel em água. Os resultados mostraram que o caráter bactericida da quitosana permanece após plastificação. Morangos revestidos com filmes de quitosana/glicerol apresentaram resistência ao ataque de fungos, e alterações insignificantes em seu sabor, aparência, aroma e textura foram observadas a partir de uma análise sensorial. Ao prolongar a vida útil dos morangos, nota-se que o filme fino desenvolvido tem grande potencial para aplicação como camada protetora de frutas e vegetais.
\end{abstract}

\section{INTRODUÇÃO}

Com o maior interesse da população por alimentos mais naturais e frescos, a indústria alimentícia e os produtores agrícolas estão mais preocupados em atender essa demanda. Um dos desafios dos produtos com menor grau de processamento é o prazo de validade, já que alimentos naturais e sem conservantes são afetados mais facilmente pela degradação causada por microrganismos, que diminuem seu tempo de prateleira ${ }^{1}$. Pensando nisso, aumentar a vida útil dos alimentos tem sido alvo de várias pesquisas, com o desafio de manter as propriedades desejadas dos alimentos. 


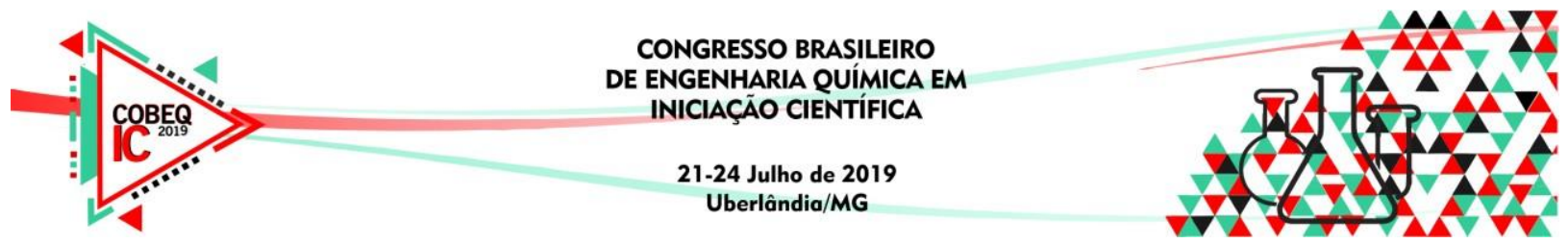

A quitosana é um biopolímero obtido através do processo de desacetilação da quitina, um polímero natural renovável ${ }^{2}$. Com um valor de pKa em torno de 6 , a quitosana é considerada um polímero catiônico que pode ser solúvel em soluções acidas. Devido a sua carga positiva, é adequada para aplicações em diversas áreas, como farmacêutica e alimentícia ${ }^{3}$.

Uma de suas particularidades é sua propriedade antibacteriana, já conhecida frente alguns tipos de bactérias, como Escherichia coli e Staphylococcus aureus ${ }^{4-6}$. Uma das explicações para tal propriedade é que, além de alterar a permeabilidade da membrana celular da bactéria, ao impedir a troca gasosa entre interior e exterior da célula, também causa disfunção celular ao romper a membrana ${ }^{2,5,7}$. Além disso, também apresenta capacidade antifúngica. $\mathrm{O}$ crescimento dos fungos é impedido pela quitosana através de interação com sua parede celular e ela também pode interferir na atividade das enzimas que são responsáveis pelo crescimento desse microrganismo, dependendo de alguns fatores, como: $\mathrm{pH}$ do meio, concentração e o grau de desacetilação da quitosana ${ }^{8}$.

Estudos voltados ao revestimento de morangos a base de quitosana têm sido feitos ${ }^{9-13}$, e os resultados mostram eficiência em tal método. Mesmo assim, são requeridos aprimoramentos nas técnicas utilizadas, para que haja extensão da vida de prateleira das frutas. Além disso, o morango é um alimento muito frágil e sensível, o que o torna suscetível ao ataque de microrganismos, como os já citados. Portanto, há o interesse de se produzir embalagens ecológicas e comestíveis para seu revestimento. Assim, filmes finos de quitosana para encobrimento de morangos, pelo método drop-casting, é o objetivo desse trabalho. Tal revestimento tem também a finalidade de proteção mecânica e biológica, devido a degradação causada por fungos e bactérias. Para saber se esse método de proteção não afetou suas características físico-químicas, foi feita uma análise sensorial, para testar a aceitabilidade dos consumidores. Os resultados obtidos mostraram-se satisfatórios para todos os parâmetros.

\section{MATERIAIS E MÉTODOS}

\subsection{Preparação e caracterização de filmes de quitosana}

Filmes finos à base de quitosana (grau de desacetilação de $78 \%$, peso molecular de $113 \mathrm{KDa}(\mathrm{Mn})$ e índice de polidispersão de 4,2) foram produzidos pela técnica de dropcasting, que consiste na evaporação controlada do solvente quando a solução contendo o material polimérico é colocado em um substrato adequado. Formas de silicone foram utilizados como substratos, pois garantem a remoção completa dos filmes após a formação. A solução precursora dos filmes foi uma solução de quitosana contendo $1 \%(\mathrm{~m} / \mathrm{m})$ de polímero em uma mistura de solventes contendo $0,5 \%(\mathrm{v} / \mathrm{v})$ de ácido acético em água. $\mathrm{O}$ glicerol foi utilizado como agente plastificante para cadeias de quitosana na proporção de $30 \%(\mathrm{~m} / \mathrm{m})$ em relação à massa de quitosana. A adição de plastificante modifica as propriedades mecânicas dos filmes, pois reduzem as forças intermoleculares das cadeias poliméricas, criando um volume livre maior que confere elasticidade ao filme.

Para a formação de filmes, $3 \mathrm{~mL}$ de solução foram adicionados às formas de silicone. O solvente foi então evaporado usando diferentes métodos para otimizar a produção dos filmes e também para evitar formação de bolhas. Os métodos empregados para a evaporação foram: i) em estufa a $40^{\circ} \mathrm{C}$; ii) seco ao ar à temperatura ambiente de $25^{\circ} \mathrm{C}$; e iii) à temperatura ambiente com o fluxo de ar ligado. 


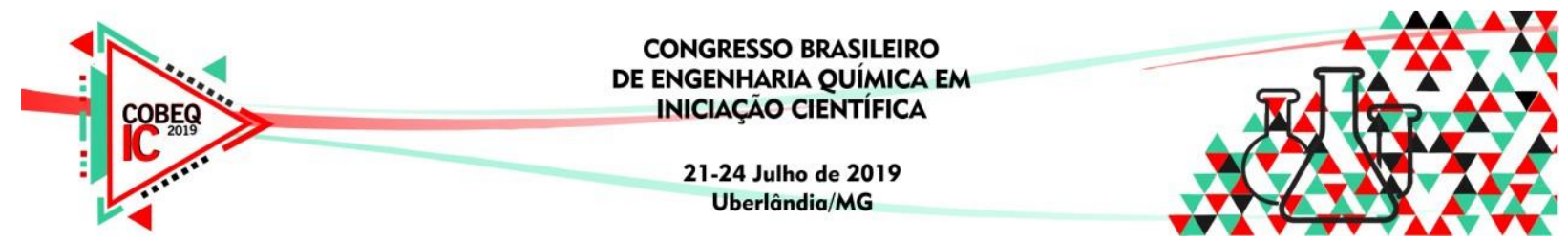

\subsection{Análises bactericidas e fungicidas}

Após a preparação, os filmes de quitosana foram testados para verificar a multiplicação de E. coli, S. aureus e B. cereus pela técnica de disco-difusão. As bactérias foram diluídas para uma concentração de $105 \mathrm{CFU} / \mathrm{ml}$. Em seguida, os discos de filmes foram colocados na superfície de placas contendo Agar (PCA) semeado com microrganismos. As placas foram incubadas a $37^{\circ} \mathrm{C}$ por 24 horas.

A eficiência do filme em relação à inibição dos fungos foi obtida usando morangos recobertos com filmes à base de quitosana. Morangos revestidos e não revestidos, mantidos dentro de caixas de acrílico fechadas a uma temperatura controlada de aproximadamente $25^{\circ} \mathrm{C}$, foram observados visualmente por uma micro câmera durante uma semana. Os morangos foram previamente sanitizados com solução de hipoclorito de sódio a $1 \%$, revestidos por imersão na solução de filme e depois secos em condições ambientais dentro do laboratório por 24 horas para garantir a formação da película à base de quitosana em sua superfície.

\subsection{Análise sensorial}

A análise sensorial foi realizada no laboratório de análise sensorial do Instituto de Ciências Exatas e Tecnológicas da Universidade Federal do Triângulo Mineiro após aprovação do Comitê de Ética em Pesquisa sob o número 2.108.891. Para a análise, 50 provadores não treinados responderam a um teste de aceitação com uma escala hedônica de 9 pontos contendo termos definidos para avaliar o gosto e a preferência.

Morangos controlados (sem biofilme ativo) e morangos revestidos com filmes de quitosana com 30\% de glicerol foram preparados. No dia anterior à análise, os morangos foram limpos com solução de hipoclorito de sódio a $1 \%$ e secos. Os morangos foram cortados ao meio e as folhas foram removidas. 50 peças receberam o revestimento com o filme de quitosana e 50 pedaços foram usadas como controle. As amostras foram servidas em copos descartáveis de $25 \mathrm{~mL}$ identificados com código numérico aleatório de três dígitos. Eles foram todos servidos simultaneamente.

\section{RESULTADOS E DISCUSSÃO}

Filmes à base de quitosana obtidos de uma solução $(1 \% \mathrm{~m} / \mathrm{m})$ com alta concentração (muito viscosa) de quitosana foram formados por diferentes formas de evaporação do solvente. Para a formação de filmes por drop-casting, tanto a taxa de evaporação do solvente quanto a de evaporação foram determinantes para a obtenção de filmes mais homogêneos (lisos) e livres de bolhas. Para obter tais filmes, foram realizadas tentativas de secagem em estufa a $40{ }^{\circ} \mathrm{C}$, na bancada de laboratório e na bancada posicionada na direção do fluxo de ar condicionado. Os filmes que secaram na estufa e na bancada do laboratório apresentaram alta concentração de bolhas. Este problema foi resolvido pela passagem do fluxo de ar suave e contínuo através dos filmes em processo de formação utilizando o fluxo de ar conectado à capela do laboratório, obtendo filmes homogêneos. No entanto, os filmes de quitosana pura eram bastante frágeis, apresentando uma elasticidade insignificante. Para promover melhorias mecânicas nos filmes de quitosana foi utilizado o glicerol como molécula plastificante. Como consequência, as propriedades do material, como a elasticidade, foram melhoradas. 


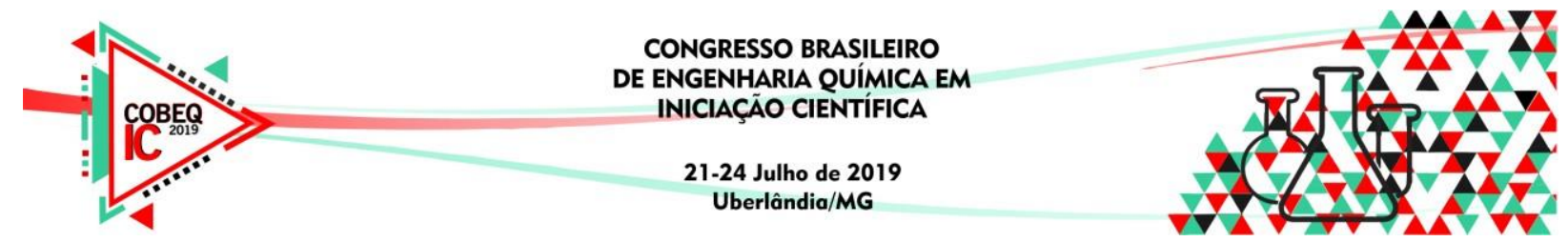

A quitosana possui grande afinidade com água através sua estrutura polar. Tal característica se torna um problema quando ela é utilizada em soluções aquosas, já que ela é empregada para proteger os alimentos, e precisa "grudar" na fruta, e não solubilizar. Portanto, pode-se utilizar glicerol para aumentar a resistência do filme à permeação em água, por ser uma substancia hidrofóbica.

Além de suas propriedades bactericidas e fungicidas, a quitosana também é utilizada por ser um filme incolor e insipido, que garante que a aparência, cor e sabor da fruta sejam preservados quando o revestimento ocorre. A atividade antibacteriana da quitosana é amplamente conhecida e relatada em vários trabalhos da literatura ${ }^{14}$, e essa atividade também foi comprovada na solução contendo glicerol.

O filme contendo quitosana com $30 \%$ de glicerol foi usado para revestir morangos, a fim de aumentar sua vida útil. Além de suas propriedades bactericidas, a quitosana também apresenta propriedades antifúngicas relatadas na literatura ${ }^{15,16}$, que puderam ser comprovadas neste trabalho, conforme a Figura 1. As figuras $1 \mathrm{~A}$ e $1 \mathrm{~B}$ representam o morango revestido com filme de quitosana com $30 \%$ de glicerol e sem revestimento, respectivamente. As fotografias $1 \mathrm{C}$ e $1 \mathrm{D}$ foram obtidas 7 dias após o recobrimento. Observou-se claramente que o morango não revestido foi totalmente tomado por fungos, enquanto o morango revestido não apresentou manifestação fúngica nesse período, fato observado atraves da análise visual com o auxílio de uma micro camera. Além disso, também foi possível perceber que a película de quitosana aderiu perfeitamente à superfície do morango, uma vez que não houve alterações em sua aparência. Isso representa uma característica importante para a aceitação dos frutos revestidos pelos consumidores. Após esse período, o morango revestido passou a sofrer algumas modificações em sua aparência, como a presença de pontos mais escuros indicando o início do apodrecimento dos frutos. No entanto, essa podridão não foi acompanhada pelo crescimento de fungos. Tal observação é uma evidência da atividade antifúngica da quitosana.

Figura 1: Imagens de a) morango revestido com filme e b) sem revestimento no dia 0; e c) morango revestido com filme e d) sem revestimento após 7 dias.
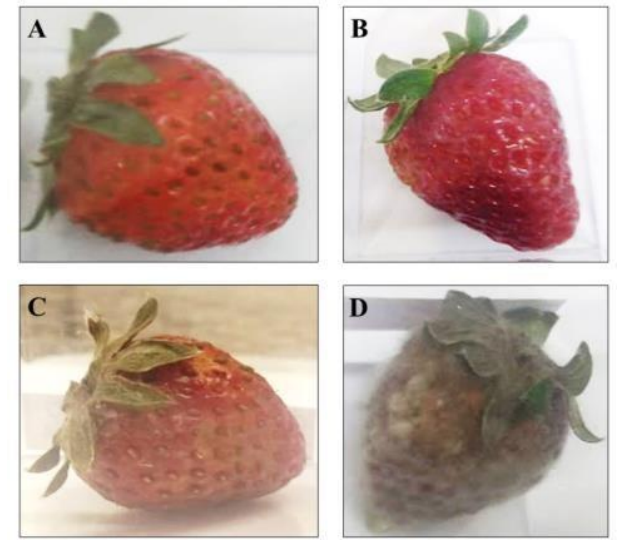

O morango é uma fruta suscetível a vários tipos de patógenos. O principal fungo que ataca a fruta pós-colheita é o chamado mofo-cinza, causado pela Botrytics cinerea, um fungo filamentoso da família Sclerotiniaceae. Após a contaminação da fruta, a colonização ocorre muito rapidamente e, em pouco tempo, a fruta é completamente tomado pelo fungo.

Uma das preocupações sobre o revestimento de morangos com filmes de quitosana foi a aceitação do consumidor. Isto pode ser determinado pela análise sensorial do fruto com e sem revestimento de quitosana. Cinquenta amostras revestidas e não revestidas (um total de 100) foram preparadas e utilizadas para a análise sensorial realizada com provadores masculinos e femininos com idades entre 20 e 40 anos. Todas as respostas são ilustradas na forma de um 


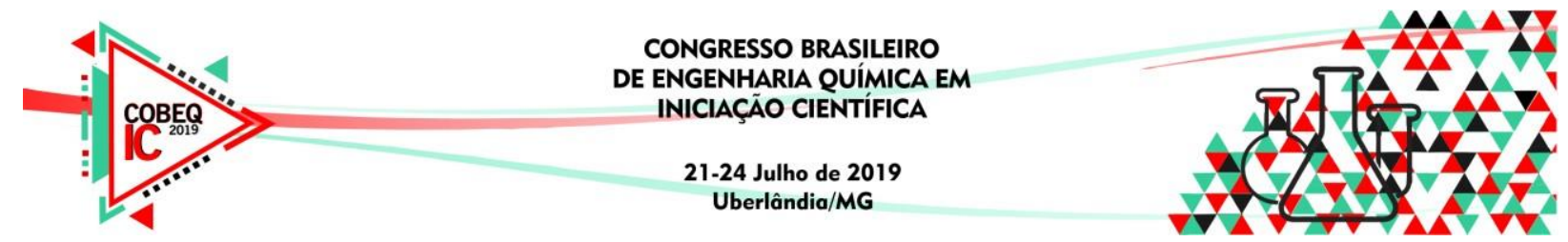

gráfico de radar na Figura 2. Pode-se observar que a aceitação do morango revestido foi alta, uma vez que a pontuação dada pelos provadores ao morango revestido não apresentou diferença significativa em relação àquela dada aos morangos não revestidos, considerando que os valores médios das pontuações têm um erro associado de $\pm 0,5$ pontos. É importante ressaltar que esses dados mostram que o revestimento com filme de quitosana com $30 \%$ de glicerol não afetou significativamente a aparência, aroma, textura e sabor do morango. Por fim, análises microbiológicas foram realizadas nos morangos revestidos e não-revestidos utilizados nas análises sensoriais em relação ao crescimento de coliformes termotolerantes e salmonelas. As respostas foram negativas para ambos os casos.

Figura 2: Respostas dadas pelos provadores durante a análise sensorial dos morangos revestidos e não revestidos.

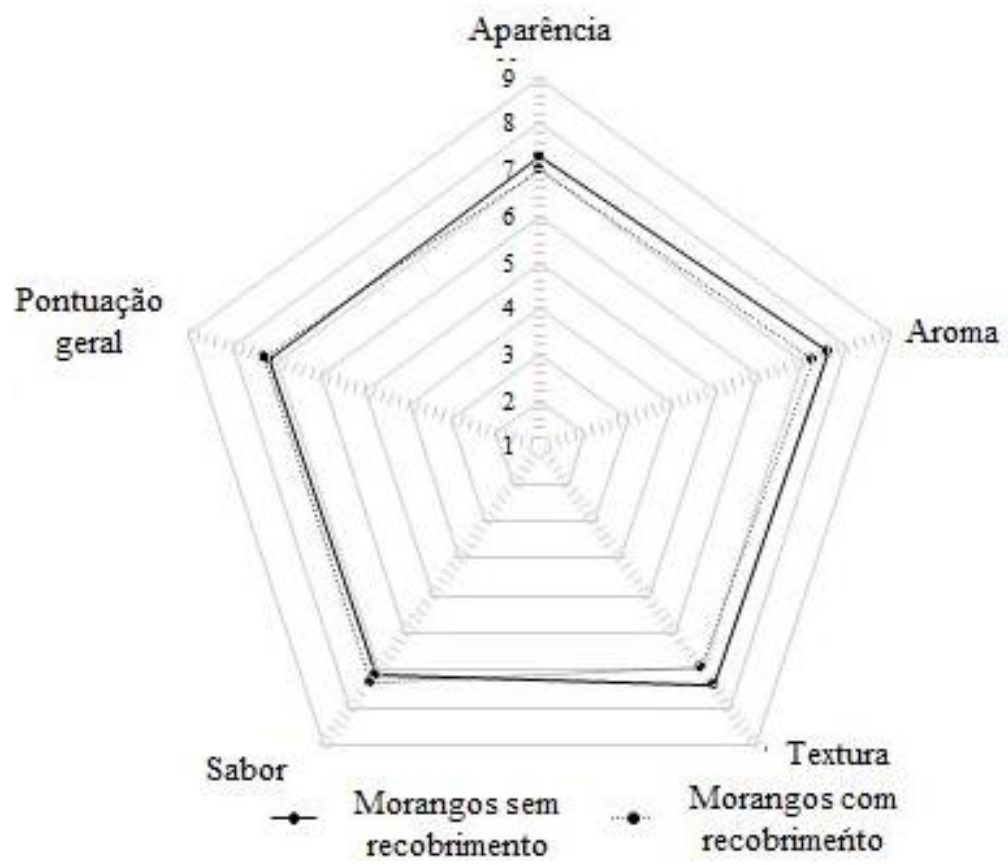

\section{CONCLUSÃo}

Filmes à base de quitosana contendo glicerol foram obtidos com sucesso para o revestimento de morangos, proporcionando proteção microbiológica ao fruto. Os filmes apresentaram menor solubilidade em meio ácido como resultado da presença de glicerol, que atuou como plastificante das moléculas do polímero. Os filmes mostraram excelente atividade bactericida e fungicida por 1 semana, o que pôde ser verificado por testes de crescimento bacteriano ou observação visual da ausência de formação de fungos em morangos revestidos. O revestimento utilizando filmes de quitosana não alterou a aparência, aroma, textura e sabor dos morangos, garantindo assim uma boa aceitação do fruto revestido. Por essa razão, esses filmes podem ser satisfatoriamente aplicados como camadas protetoras para alimentos frescos, como morangos.

\section{REFERÊNCIAS}

(1) Rawat, S. Food Spoilage: Microorganisms and Their Prevention. Pelagia Res. Libr. Asian J. Plant Sci. Res. 2015, 5 (4), 47-56.

(2) Elsabee, M. Z.; Abdou, E. S. Chitosan Based Edible Films and Coatings: A Review. 


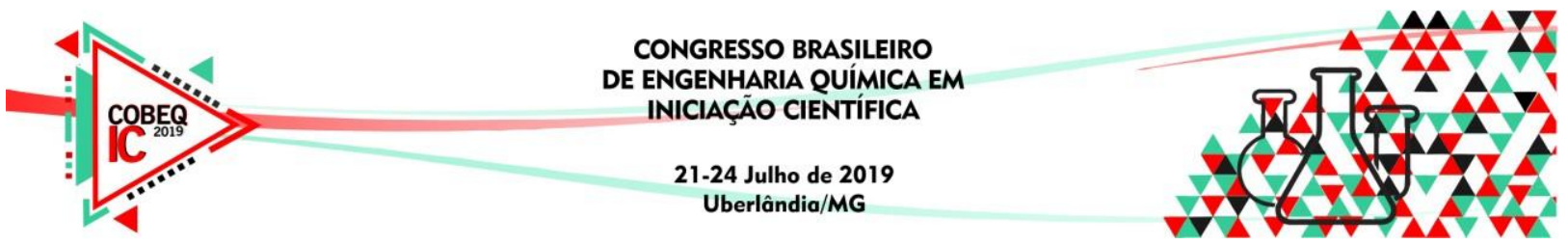

Mater. Sci. Eng. C 2013, 33 (4), 1819-1841.

(3) Kumar, M. N. V. R. A-Review-of-Chitin-and-Chitosan applications_2000_Reactive-and-Functional-Polymers. 2000, 46, 1-27.

(4) Costa, E. M.; Silva, S.; Vicente, S.; Neto, C.; Castro, P. M.; Veiga, M.; Madureira, R.;Tavaria, F.; Pintado, M. M. Chitosan Nanoparticles as Alternative Anti-Staphylococci Agents: Bactericidal, Antibiofilm and Antiadhesive Effects. Mater. Sci. Eng. C 2017, 79, 221226.

(5) Goy, R. C.; Morais, S. T. B.; Assis, O. B. G. Evaluation of the Antimicrobial Activity of Chitosan and Its Quaternized Derivative on E. Coli and S. Aureus Growth. Brazilian J. Pharmacogn. 2016, 26 (1), 122-127.

(6) Qin, X.; Engwer, C.; Desai, S.; Vila-Sanjurjo, C.; Goycoolea, F. M. An Investigation of the Interactions between an E. Coli Bacterial Quorum Sensing Biosensor and ChitosanBased Nanocapsules. Colloids Surfaces B Biointerfaces 2017, 149, 358-368.

(8) Singh, R.; Shitiz, K.; Singh, A. Chitin and Chitosan: Biopolymers for Wound Management. Int. Wound J. 2017, 14 (6), 1276-1289.

(9) Goy, R. C.; Britto, D. de; Assis, O. B. G. A Review of the Antimicrobial Activity of Chitosan. Polímeros 2009, 19 (3), 241-247.

(10) Khalifa, I.; Barakat, H.; El-Mansy, H. A.; Soliman, S. A. Improving the Shelf-Life Stability of Apple and Strawberry Fruits Applying Chitosan-Incorporated Olive Oil Processing Residues Coating. Food Packag. Shelf Life 2016, 9, 10-19.

(11) Resende, N. S.; Gonçalves, G. A. S.; Reis, K. C.; Tonoli, G. H. D.; Boas, E. V. B. V. Chitosan/Cellulose Nanofibril Nanocomposite and Its Effect on Quality of Coated Strawberries. J. Food Qual. 2018, 2018.

(12) Barikloo, H.; Ahmadi, E. Shelf Life Extension of Strawberry by Temperatures Conditioning, Chitosan Coating, Modified Atmosphere, and Clay and Silica Nanocomposite Packaging. Sci. Hortic. (Amsterdam). 2018, 240 (June), 496-508.

(13) Barikloo, H.; Ahmadi, E. Effect of Nanocomposite-Based Packaging and Chitosan Coating on the Physical, Chemical, and Mechanical Traits of Strawberry during Storage. J. Food Meas. Charact. 2018, 12 (3), 1795-1817.

(14) Duran, M.; Aday, M. S.; Zorba, N. N. D.; Temizkan, R.; B??y??kcan, M. B.; Caner, C. Potential of Antimicrobial Active Packaging "Containing Natamycin, Nisin, Pomegranate and Grape Seed Extract in Chitosan Coating" to Extend Shelf Life of Fresh Strawberry. Food Bioprod. Process. 2016, 98, 354-363.

(15) Xu, W.; Xie, W.; Huang, X.; Chen, X.; Huang, N.; Wang, X.; Liu, J. The Graphene Oxide and Chitosan Biopolymer Loads $\mathrm{TiO} 2$ for Antibacterial and Preservative Research. Food Chem. 2017, 221, 267-277.

(16) Romanazzi, G.; Feliziani, E.; Landi, L. Preharvest Treatments with Alternatives to Conventional Fungicides to Control Postharvest Decay of Strawberry. Acta Hortic. 2016, 1117, 111-117.

(17) Costa, E. M.; Silva, S.; Vicente, S.; Veiga, M.; Tavaria, F.; Pintado, M. M. Chitosan as an Effective Inhibitor of Multidrug Resistant Acinetobacter Baumannii. Carbohydr. Polym. 2017, 178 (September), 347-351. 